EXTENDED REPORT

\title{
Radiological sacroiliitis, a hallmark of spondylitis, is linked with CARD15 gene polymorphisms in patients with Crohn's disease
}

\author{
H Peeters, B Vander Cruyssen, D Laukens, P Coucke, D Marichal, M Van Den Berghe, C Cuvelier, \\ E Remaut, H Mielants, F De Keyser, M De Vos
}

Ann Rheum Dis 2004;63:1131-1134. doi: 10.1136/ard.2004.021774

See end of article for authors' affiliations

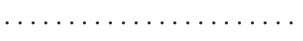

Correspondence to: Dr Harald Peeters, Department of Gastroenterology, Ghent University Hospital B-9000 Ghent, Belgium; harald.peeters@UGent.be

Accepted 27 April 2004

\begin{abstract}
Background: Sacroiliitis is a common extraintestinal manifestation of Crohn's disease but its association with the HLA-B27 phenotype is less evident. Polymorphisms in the CARD15 gene have been linked to higher susceptibility for Crohn's disease. In particular, associations have been found with ileal and fibrostenosing disease, young age at onset of disease, and familial cases.

Objectives: To investigate whether the presence of sacroiliitis in patients with Crohn's disease is linked to the carriage of CARD15 polymorphisms.

Methods: 102 consecutive patients with Crohn's disease were clinically evaluated by a rheumatologist. Radiographs of the sacroiliac joints were taken and assessed blindly by two investigators. The RFLP-PCR technique was used to genotype all patients for three single nucleotide polymorphisms (SNP) in the CARD15 gene. Every SNP was verified by direct sequencing. The HLA-B27 phenotype was determined. Results: Radiological evidence of sacroiliitis with or without ankylosing spondylitis was found in 23 patients (23\%), of whom only three were HLA-B27 positive. In contrast, $78 \%$ of patients with sacroiliitis carried a CARD 15 variant $v 48 \%$ of those without sacroiliitis $(p=0.01$; odds ratio $3.8195 \%$ confidence interval, 1.3 to 11.5)). Multivariate analysis (logistic regression) showed that the association between sacroiliitis and CARD1 5 polymorphisms was independent of other CARD15 related phenotypes (ileal and fibrostenosing disease, young age at onset of disease, familial Crohn's disease) $(p=0.039)$.

Conclusions: CARD1 5 variants were identified as genetic predictors of Crohn's disease related sacroiliitis. An association was demonstrated between these polymorphisms and an extraintestinal manifestation of Crohn's disease.
\end{abstract}

$\mathrm{T}$ here is increasing evidence that Crohn's disease is a multigenic disorder resulting in different phenotypes. ${ }^{1}$ Although several susceptibility loci have been described, only one gene has been clearly identified as being associated with an increased susceptibility to Crohn's disease. Three single nucleotide polymorphisms (SNP) in the CARD15 gene (R702W, G908R, and 1007fs) increase the risk for Crohn's disease by a factor of 3 for heterozygotes and by about a factor of 40 for homozygotes or compound heterozygotes. ${ }^{2-4}$

The identification of associated phenotypes remains unclear and controversial but suggests an association with ileal and fibrostenosing disease, familial predisposition, and earlier age at onset. ${ }^{5-8}$

No association has been reported between CARD15 polymorphisms and extraintestinal manifestations of Crohn's disease. However, data on articular involvement are scarce and limited to two studies. ${ }^{67}$ Lesage et al reported articular involvement in only $6 \%$ of the patients, but without a clear definition and without separation between peripheral and axial disease. ${ }^{6}$ Ahmad et al recorded pauciarticular arthritis in $13 \%$ of the patients, also with no information about axial disease. ${ }^{7}$ The data in these studies were gathered through questionnaires and the patients' clinical records.

Besides Crohn's disease, CARD15 variants have also been linked to Blau syndrome and psoriatic arthritis. ${ }^{9}{ }^{10}$ Current data show no association between CARD15 and idiopathic ankylosing spondylitis (AS $)^{11-14}$; however, in the Crohn's disease variant the HLA-B27 association is weaker than in idiopathic AS, pointing to another genetic link. ${ }^{15-17}$ Indeed, Van der Paardt et al have already suggested that it would be interesting to determine whether there is an association between CARD15 and the subgroup of patients with Crohn's disease and AS. ${ }^{12}$

Our aim in this cross sectional clinical and radiological study was to evaluate, in a cohort of Crohn's disease patients, the possible association between CARD15 polymorphisms and the presence of radiological sacroiliitis, a hallmark of spondylitis and the most frequent objective rheumatic manifestation of Crohn's disease. ${ }^{18}$

\section{METHODS}

\section{Study population}

One hundred and two white patients with Crohn's disease, attending the gastroenterology department of the Ghent University Hospital, agreed to participate in this cross sectional study and were included consecutively over a period of 13 months. The diagnosis of Crohn's disease was based on clinical, endoscopic, histological, and radiological findings. All patients were seen by both a gastroenterologist and a rheumatologist. The localisation of the disease was assessed as ileal, ileocolonic, or colonic. Types and amount of surgical interventions were recorded. The need for resective small bowel surgery was used as an index of fibrostenosing disease. A positive family history was defined as the presence of at least one first, second, or third degree relative with

Abbreviations: AS, ankylosing spondylitis; CARD, caspase activation and recruitment domain; IBD, inflammatory bowel disease; RFLP-PCR, restriction fragment length polymorphism polymerase chain reaction; SNP, single nucleotide polymorphism 
proven Crohn's disease. The age at diagnosis of the disease was also recorded.

For controls, we used a group of 54 patients without any symptoms or clinical evidence of Crohn's disease, spondyloarthropathies, or sclerosing cholangitis, who were attending the department of hepatology.

The study was approved by the regional ethics committee and all patients gave their signed informed consent.

\section{Assessment of articular involvement}

All patients were assessed for the presence of inflammatory low back pain, had measurements of the Schöber index and chest expansion, and were examined for peripheral arthritis and enthesopathy (fasciitis plantaris or Achilles tendon tendinitis).

A history of peripheral arthritis or enthesopathy was recorded if observed, confirmed by a physician, and noted in the patient's medical record. Inflammatory low back pain was defined by the history or presence of spinal pain in the neck, dorsal, or cervical region with at least four of the five following criteria: onset before the age of 45 years, insidious onset, improvement with exercise, association with morning stiffness, and duration of at least three months. ${ }^{19}$ The modified New York criteria were used to determine the diagnosis of $\mathrm{AS}^{20}$

\section{Radiological classification}

Radiographs of the sacroiliac joints were made and assessed blindly by two rheumatologists. They were scored using the New York grading system: 0, normal; 1, suspicious; 2, localised sclerosis, erosion, joint widening; 3 , diffuse sclerosis, erosion, widening; 4, ankylosis..$^{20}$ Radiological sacroiliitis was diagnosed by the presence of at least unilateral sacroiliitis grade 2, and only when agreed on by both radiological assessors. ${ }^{1821}$

\section{CARD 15 and HLA-B27 typing}

Genomic DNA was extracted from whole blood using a Qiagen blood and cell culture DNA kit (Qiagen, Valencia, California, USA).

All patients were genotyped for R702W (SNP8), G908R (SNP12), and 1007fs (SNP13) using a restriction fragment length polymorphism polymerase chain reaction technique (RFLP-PCR), followed by separation on $2.5 \%$ agarose gel. The missense mutation R702W (GenBank accession number G67950) abolishes the restriction site for MspI (5'-CAGCCC TGATGACATTTCTCTT-3' and 5'-AGCCGCTCCTCCTGCATCTC GTA-3'), resulting in an intact 130 base pair (bp) band for mutant alleles, compared with two bands of 54 and 76 bp for wild type alleles. The missense mutation G908R (GenBank accession number G67951) creates a restriction site for HinP1l. The frameshift mutation 1007fs (GenBank accession number G67955) creates a restriction site for NlaIV (5'-

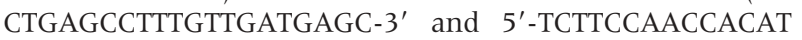
CCCCATT-3'). The presence of a mutant allele results in two bands of 219 and $41 \mathrm{bp}$, while the wild type allele produces a single $260 \mathrm{bp}$ product. We verified every SNP by direct sequencing of the PCR product in an ABI 377 analyser (Applied Biosystems, Foster City, California, USA).

HLA-B27 typing was undertaken using Dynal Classic SSP (Dynal Biotech, Bromborough, Cheshire, UK).

\section{Statistical analysis}

Odds ratios were calculated with Pearson's $\chi^{2}$ test or Fisher's exact test when the expected count was less than 5 in at least one cell. A model for multivariate analysis (logistic regression) was constructed, with sacroiliitis as the dependent variable. As covariates we included the CARD15 genotype, HLA-B27, and CARD15 related phenotypes. A probability (p) value of less than 0.05 was considered to indicate statistical significance. Statistical analyses was carried out using SPSS software (SPSS Inc, Chicago, Illinois, USA).

\section{RESULTS}

\section{Patient characteristics}

In all, 102 patients with Crohn's disease were included (34 men, 68 women), mean age 41.6 years (range 18 to 71 ). The mean age at diagnosis was 28.5 years (range 9 to 57 ). Twenty two of the patients (21.6\%) had ileal disease, 26 (25.5\%) had colonic disease, and 54 (52.9\%) had ileocolonic involvement. Fifty two patients $(51.0 \%)$ had needed resection of a small bowel segment. Fifteen patients (14.7\%) had a family history of Crohn's disease.

\section{Radiological sacroiliitis and other rheumatic manifestations}

Radiological sacroiliitis was found in 23 patients: eight had unilateral sacroiliitis grade 2, 14 had bilateral sacroiliitis grade 2, and one had unilateral sacroiliitis grade 3 . Nine patients fulfilled the criteria for AS. Among the 14 remaining patients, three had inflammatory low back pain without fulfilling the AS criteria, and 11 were clinically asymptomatic.

The history or presence of peripheral arthritis was recorded in 17 patients, of whom five actually had arthritis at the time of study assessment. Three patients had monoarticular arthritis and 14 had oligoarticular involvement. A history of enthesopathy was present in 11 patients, of whom four had tendinitis at the time of the study.

\section{CARD 15 status}

The overall prevalence of CARD15 polymorphisms in the Crohn's disease group was significantly higher than in the control group, at 56/102 (54.9\%) v 8/54 (15\%), p<0.001; odds ratio (OR) 7.00 (95\% confidence interval (CI), 3.00 to 16.31$)$ ). Eighteen of 23 patients with radiological sacroiliitis (78\%) carried at least one CARD 15 variant, compared with 38 of 79 patients $(48 \%)$ without sacroiliitis $(\mathrm{p}=0.01$; OR 3.88 (95\% CI, 1.31 to 11.49)) (table 1). There were two compound heterozygotes and no homozygotes in the group of patients with sacroiliitis (table 1). Seven of nine patients with AS carried a CARD15 variant (table 2).

In another perspective, among all carriers of CARD15 variants, $32 \%$ of the patients had sacroiliitis compared with $11 \%$ in patients without these variants.

Table 1 Carrier frequency of CARD1 5 variants in patients with Crohn's disease

\begin{tabular}{|c|c|c|c|c|}
\hline & R702W & G908R & $1007 \mathrm{fs}$ & Overall* \\
\hline \multicolumn{5}{|c|}{ Crohn's disease $(n=102)$} \\
\hline CARDI5+/- & 33 & 6 & 21 & \multirow{2}{*}{56} \\
\hline CARDI5+/+ & 2 & 1 & 0 & \\
\hline \multicolumn{5}{|c|}{ Crohn's disease with no SI ( $n=79)$} \\
\hline CARD15+/- & 21 & 6 & 13 & \multirow[b]{2}{*}{38} \\
\hline CARD15+/+ & 2 & 1 & 0 & \\
\hline \multicolumn{5}{|c|}{ Crohn's disease with SI (n=23) } \\
\hline CARD15+/- & 12 & 0 & 8 & \multirow{2}{*}{18} \\
\hline CARDI5+/+ & 0 & 0 & 0 & \\
\hline \multicolumn{5}{|c|}{$\begin{array}{l}\text { Numbers of patients carrying R702W, G908R, or } 1007 \mathrm{fs} \text { variants. } \\
{ }^{*} \text { Total number of patients in the group carrying at least one variant. The } \\
\text { sum of all allelic CARD15 variants is greater than the overall number of } \\
\text { patients carrying at least one variant, as some patients carry two different } \\
\text { single nucleotide polymorphisms (compound heterozygotes). } \\
\text { CARD15+/-, heterozygous for CARD15 gene; CARD15+/+, } \\
\text { homozygous for CARD15 gene; SI, sacroiliitis. }\end{array}$} \\
\hline
\end{tabular}


Table 2 Carrier frequency of CARD15 variants and HLA-B27 in patients with Crohn's disease

\begin{tabular}{lll}
\hline & CARD15 $+/-$ or $+/+$ & HLA-B27+ \\
\hline Total $(n=102)$ & $56(55 \%)$ & $6(6 \%)$ \\
No sacroiliitis $(n=79)$ & $38(48 \%)$ & $3(4 \%)$ \\
Sacroiliitis $(n=23)$ & $18(78 \%)$ & $3(13 \%)$ \\
AS $(n=9)$ & 7 & 3 \\
Non-AS $(n=14)$ & 11 & 0
\end{tabular}

CARD $15+$ / - or +/+: carriage of at least 1 CARD 15 variant HLA-B27+: carriage of HLA-B27

AS, Crohn's disease patients with sacroiliitis fulfilling the ankylosing spondylitis (AS) criteria; non-AS, Crohn's disease patients with sacroiliitis not fulfilling the AS criteria.

There was no significant association between the presence of CARD15 polymorphisms and peripheral arthritis $(\mathrm{p}=0.37$; OR $1.6(95 \%$ CI, 0.55 to 4.81$)$ ) or enthesopathy ( $\mathrm{p}=0.34$; OR $0.5(0.14$ to 1.94$))$.

\section{HLA-B 27 status}

Overall, six of the 102 patients with Crohn's disease $(6 \%)$ carried HLA-B27. HLA-B27 positivity was present in three of the 23 patients $(13 \%)$ with sacroiliitis. Those three patients were also carriers of CARD15 variants and fulfilled the modified New York criteria for AS (table 2).

\section{Multivariate analysis}

Logistic regression showed the presence of CARD15 variants as the only significant predictor of sacroiliitis $(p=0.039)$, independent of HLA-B27, ileal involvement, need for resective small bowel surgery, familial Crohn's disease, or age at onset (table 3 ).

\section{DISCUSSION}

Our data identify CARD15 variants as a possible genetic predictor of sacroiliitis in Crohn's disease. Sacroiliitis is a distinct extraintestinal manifestation of Crohn's disease. In contrast to the clinically evident peripheral arthritis, the prevalence of axial involvement in Crohn's disease is probably underestimated..$^{182}$ Previous studies showed that $10-32 \%$ of patients with inflammatory bowel disease (IBD) have evidence of sacroiliitis, a hallmark of spondylitis, on conventional radiography. ${ }^{15} 171821{ }^{23-25}$ With technetium scintigraphy, tracer uptake in the sacroiliac joints can be seen in up to $52 \%$ of patients. ${ }^{26}$ Many patients with sacroiliitis remain asymptomatic. $^{1517182327}$ Only about one quarter of the patients with radiological sacroiliitis also fulfil the criteria for AS. $^{18}$ In contrast to idiopathic AS, involvement of the sacroiliac joints is asymmetrical in about $25 \%$ of the patients with Crohn's disease. ${ }^{18} 2122$

In our cohort, $23 \%$ of patients had evidence of sacroiliitis of at least grade 2 unilaterally on conventional radiographs. Diagnosis of AS was retained in 39\% of these patients with sacroiliitis.

In contrast to other forms of spondyloarthropathy, the association between axial involvement and HLA-B27 is weak in IBD patients. Whereas HLA-B27 is present in more than $90 \%$ of patients with idiopathic AS, the prevalence decreases to $25-75 \%$ in patients with AS associated with IBD, and to low or even normal prevalences in patients with asymptomatic IBD-associated radiological sacroiliitis. ${ }^{15-17} 24$

Recently, the possibility of an as yet undefined common genetic link between intestinal inflammation and sacroiliac changes was again suggested in a study assessing first degree relatives of patients with AS. ${ }^{28}$ This study showed an association between asymptomatic intestinal inflammation, recorded in $41 \%$ of these relatives, and sacroiliac changes
Table 3 Multivariate analysis (logistic regression) with "sacroiliitis" as the dependent variable

\begin{tabular}{llll}
\hline Covariate & p Value & OR & $95 \% \mathrm{Cl}$ \\
\hline CARD15 variants & 0.039 & 3.38 & 1.06 to 10.75 \\
HLA-B27 & 0.201 & 3.48 & 0.51 to 23.81 \\
lleal involvement & 0.517 & 1.84 & 0.29 to 11.49 \\
History of small bowel resection & 0.145 & 2.56 & 0.72 to 9.09 \\
Family history of Crohn's disease & 0.857 & 1.14 & 0.28 to 4.65 \\
Age at diagnosis & 0.706 & 0.99 & 0.94 to 1.04
\end{tabular}

Logistic regression shows that the association between sacroiliitis and CARD 15 variants is independent of known CARD 15 related phenotypes or HLA-B27.

$\mathrm{Cl}$, confidence interval; $\mathrm{OR}$, odds ratio

suggestive of early AS. The presence of intestinal inflammation and sacroiliac changes did not relate to the HLA-B27 status of these subjects.

Our data suggest that CARD15 polymorphisms may predispose to sacroiliac involvement in Crohn's disease: $78 \%$ of Crohn's patients with sacroiliitis carried at least one variant, versus $48 \%$ of patients without sacroiliitis. Multivariate analysis showed that the presence of CARD15 variants was the only significant predictor of sacroiliitis, independent of other known CARD15 related phenotypes such as ileal involvement, fibrostenosing disease, family history, and age of onset, and independent of HLA-B27.

Interestingly, the three patients with sacroiliitis who carried HLA-B27 also carried a CARD15 variant, and all had clinical AS. In contrast none of the patients with isolated sacroiliitis carried HLA-B27. Whether or not the presence of both genetic markers in Crohn's patients with sacroiliitis predisposes to evolution to AS cannot be concluded from this study. It seems interesting, however, to explore this question with larger studies.

The percentage of Crohn's disease patients with CARD15 variants was higher in our study (54.9\%) than generally reported. A variation in the methodology was excluded as the prevalence in our control group was similar to values in previous reports. Moreover, the prevalence of CARD15 variants in our group was not significantly greater than in another Flemish population studied by Vermeire et al $(46.1 \%){ }^{29}$

To the best of our knowledge, no studies are available about a possible relation between the CARD15 genotype and sacroiliitis in Crohn's disease. Until now, studies in idiopathic AS have not been able to demonstrate a possible association with CARD 15 variants. ${ }^{11-14}$ However, these studies provided no information on the possible presence and relative number of patients with Crohn's disease who were included. Only one study included cases of AS with Crohn's disease and ulcerative colitis. ${ }^{30}$ The investigators could not demonstrate a higher prevalence of CARD15 variants in patients with AS plus Crohn's disease compared with idiopathic AS, AS plus ulcerative colitis, or healthy controls. The low prevalence of CARD15 variants in their Crohn's population with AS was not compared with the prevalence in a general Crohn's disease population. Moreover, they unexpectedly showed a possible association between the G908R CARD15 variant and AS with ulcerative colitis.

In contrast to that study, we found CARD15 variants in seven of nine Crohn's patients with AS. Although it only represents a small group of patients in our study, a difference in prevalence of CARD 15 variants between Crohn's disease related AS and idiopathic AS (and also for HLA-B27) could reflect a different aetiopathogenetic mechanism.

The CARD15 gene encodes for an intracellular protein that is found in monocytes, macrophages, epithelial cells, granulocytes, and dendritic cells. The gene product acts as a 
receptor for bacterial cell wall components like muramyldipeptides derived from peptidoglycan and lipopolysaccharides, resulting in the activation of NF- $\mathrm{\kappa B}$. The polymorphisms described could cause a disturbed cellular response to bacterial components, leading to intracellular persistence of pathogens. ${ }^{31}$ Previous studies have suggested that recirculation of inflammatory cells between the gut and peripheral joints might contribute to inflammation at a distance..$^{32-36}$

\section{Conclusions}

In Crohn's disease, CARD15 variants could play a role in the development of sacroiliitis, as an extraintestinal manifestation of the disease. However, the exact mechanism of the link between gut and axial joints remains to be elucidated.

\section{ACKNOWLEDGEMENTS}

This study was supported by a concerted action grant GOA2001/ 12051501 of Ghent University, Belgium; by grants of the Flemish Society of Crohn and Ulcerative Colitis, the Flemish Society of Gastroenterology; and Flanders Interuniversity Institute for Biotechnology (VIB).

\section{Authors' affiliations}

H Peeters, D Marichal, M D Vos, Department of Gastroenterology, Ghent University Hospital, Ghent, Belgium

B Vander Cruyssen, M Van Den Berghe, H Mielants, F De Keyser, Department of Rheumatology, Ghent University Hospital

D Laukens, E Remaut, Department of Molecular Biomedical Research-

VIB, Ghent University and Flanders Interuniversity Institute for Biotechnology (VIB), Ghent

P Coucke, Centre for Medical Genetics, Ghent University Hospital C Cuvelier, Department of Pathology, Ghent University Hospital

$\mathrm{H}$ Peeters and B Vander Cruyssen contributed equally to this work.

\section{REFERENCES}

1 Bonen DK, Cho JH. The genetics of inflammatory bowel disease. Gastroenterology 2003;124:521-36.

2 Hugot JP, Chamaillard M, Zouali H, Lesage S, Cezard JP, Belaiche J, et al. Association of NOD2 leucine-rich repeat variants with susceptibility to Crohn's disease. Nature 2001:411:599-603.

3 Ogura Y, Bonen DK, Inohara N, Nicolae DL, Chen FF, Ramos R, et al. A frameshift mutation in NOD2 associated with susceptibility to Crohn's disease. Nature $2001 ; 411: 603-6$.

4 Hampe J, Cuthbert A, Croucher PJ, Mirza MM, Mascheretti S, Fisher S, et al. Association between insertion mutation in NOD2 gene and Crohn's disease in German and British populations. Lancet 2001;357:1925-8.

5 Cuthbert AP, Fisher SA, Mirza MM, King K, Hampe J, Croucher PJ, et al. The contribution of NOD2 gene mutations to the risk and site of disease in inflammatory bowel disease. Gastroenterology 2002;122:867-74.

6 Lesage S, Zouali H, Cezard JP, Colombel JF, Belaiche J, Almer S, et al. CARD15/NOD2 mutational analysis and genotype-phenotype correlation in 612 patients with inflammatory bowel disease. Am J Hum Genet 2002;70:845-57

7 Ahmad T, Armuzzi A, Bunce M, Mulcahy-Hawce K, Marshall SE, Orchard TR, et al. The molecular classification of the clinical manifestations of Crohn's disease. Gastroenterology 2002;122:854-66.

8 Abreu MT, Taylor KD, Lin YC, Hang T, Gaiennie J, Landers CJ, et al. Mutations in NOD2 are associated with fibrostenosing disease in patients with Crohn's disease. Gastroenterology 2002;123:679-88.

9 Miceli-Richard C, Lesage S, Rybojad M, Prieur AM, Manouvrier-Hanu S, Hafner R, et al. CARD 15 mutations in Blau syndrome. Nat Genet $2001 ; 29: 19-20$

10 Rahman P, Bartlett S, Siannis F, Pellett FJ, Farewell VT, Peddle L, et al. CARD 15: a pleiotropic autoimmune gene that confers susceptibility to psoriatic arthritis. Am J Hum Gen 2003;73:677-81.

11 Miceli-Richard C, Zouali H, Lesage S, Thomas G, Hugot JP, Said-Nahal R, et al. CARD15/NOD2 analyses in spondyloarthropathy. Arthritis Rheum 2002;46:1405-6.
12 van der Paardt M, Crusius JB, de Koning MH, Murillo LS, Van de Stadt RJ, Dijkmans BA, Pena AS, et al. CARD1 5 gene mutations are not associated with ankylosing spondylitis. Genes Immun 2003;4:77-8.

13 D'Amato M. The Crohn's associated NOD2 3020InsC frameshift mutation does not confer susceptibility to ankylosing spondylitis. J Rheumatol 2002;29:2470-1.

14 Ferreiros-Vidal I, Amarelo J, Barros F, Carracedo A, Gomez-Reino JJ, Gonzales A. Lack of association of ankylosing spondylitis with the most common NOD2 susceptibility alleles to Crohn's disease. J Rheumatol 2003;30:102-4.

15 Hyla J, Franck W, Davis J. Lack of association of HLA B27 with radiographic sacroiliitis in inflammatory bowel disease. J Rheumatol 1976:3:196-200.

16 Enlow RW, Bias WB, Arnett FC. The spondylitis of inflammatory bowel disease. Evidence for a non-HLA linked axial arthropathy. Arthritis Rheum 1980;23:1359-64

17 Steer S, Jones H, Hibbert J, Kondeatis E, Vaughan R, Sanderson J, et al. Low back pain, sacroiliitis, and the relationship with HLA-B27 in Crohn's disease. J Rheumatol 2003:30:518-22.

18 de Vlam K, Mielants H, Cuvelier C, De Keyser F, Veys EM, De Vos M. Spondyloarthropathy is underestimated in inflammatory bowel disease: prevalence and HLA association. J Rheumatol 2000;27:2860-5.

19 Dougados M, van der Linden S, Juhlin R, Huitfeldt B, Amor B, Calin A, et al. The European Spondylarthropathy Study Group preliminary criteria for the classification of spondylarthropathy. Arthritis Rheum 1991;34:1218-27.

20 Van der Linden S, Valkenberg HA, Cats A. Evaluation of diagnosis criteria for ankylosing spondylitis. A proposal for modification of the New York criteria. Arthritis Rheum 1984:27:361-8.

21 Queiro R, Maiz O, Intxausti J, de Dios JR, Belzunegui J, Gonzales C, et al. Subclinical sacroiliitis in inflammatory bowel disease: a clinical and follow-up study. Clin Rheumatol 2000;19:445-9.

22 Orchard TR, Wordsworth BP, Jewell DP. Peripheral arthropathies in inflammatory bowel disease: their articular distribution and natural history. Gut 1998;42:387-91.

23 McEniff N, Eustace S, McCarthy C, O'Malley M, O'Morain CA, Hamilton S. Asymptomatic sacroiliitis in inflammatory bowel disease. Assessment by computer tomography. Clin Imaging 1995;19:258-62.

24 Dekker-Saeys BJ, Meuwissen SG, Van Den Berg-Loonen EM, De Haas WH, Agenant D, Tytgat GN. Ankylosing spondylitis and inflammatory bowel disease. II. Prevalence of peripheral arthritis, sacroiliitis and ankylosing spondylitis in patients suffering from inflammatory bowel disease. Ann Rheum Dis 1978; $37: 33-5$.

25 Ansell BM, Wigley RA. Arthritic manifestations in regional enteritis. Ann Rheum Dis 1964;23:64-72.

26 Davis $\mathbf{P}$, Thomson $A B$, Lentle $B C$. Quantitative sacroiliac scintigraphy in patients with Crohn's disease. Arthritis Rheum 1978:21:234-7.

27 Scott WW, Fishman EK, Kuhlman JE, Caskey Cl, O'Brien JJ, Walia GS, et al. Computed tomography evaluation of the sacroiliac joints in Crohn's disease. Radiologic/clinical correlation. Skel Radiol 1990;19:207-10.

28 Bjarnason I, Helgason KO, Geirsson AJ, Sigthorsson G, Reynisdottir I, Gudbjartsson D, et al. Subclinical intestinal inflammation and sacroiliac changes in relatives of patients with ankylosing spondylitis. Gastroenterology 2003; 125:1598-605

29 Vermeire S, Esters N, Pierik M, Claessens G, Joossens S, Vlietinck R, et al. Transmission of CARD15 (NOD2) variants in families with Crohn's disease [abstract]. Gastroenterology 2003;124:A368.

30 Crane AM, Bradbury L, van Heel DA, McGovern DP, Brophy S, Rubin K, et al. Role of NOD2 variants in spondylarthritis. Arthritis Rheum 2002;46:1629-33

31 Bonen DK, Ogura Y, Nicolae DL, Inohara N, Saab L, Tanabe T, et al. Crohn's disease-associated NOD2 variants share a signaling defect in response to lipopolysaccharide and peptidoglycan. Gastroenterology 2003;124:140-6.

32 Salmi M, Jalkanen S. Human leukocyte subpopulations from inflamed gut bind to joint vasculature using distinct sets of adhesion molecules. J Immunol $2001 ; 166: 4650-7$.

33 Elewaut D, De Keyser F, Cuvelier C, Lazarovits Al, Mielants H, Verbruggen G, et al. Distinctive activated cellular subsets in colon from patients with Crohn's disease and ulcerative colitis. Scand J Gastroenterol 1998;33:743-8.

34 Demetter P, Baeten D, De Keyser F, De Vos M, Van Damme N, Verbruggen G, et al. Subclinical gut inflammation in spondyloarthropathy patients is associated with upregulation of the E-cadherin/catenin complex. Ann Rheum Dis 2000;59:211-16.

35 Elewaut D, De Keyser F, Van Den Bosch F, Lazarovits Al, De Vos M Cuvelier $C$, et al. Enrichment of T cells carrying beta7 integrins in inflamed synovial tissue from patients with early spondyloarthropathy, compared to rheumatoid arthritis. J Rheumatol 1998;25:1932-7.

36 Baeten D, Demetter P, Cuvelier CA, Kruithof E, Van Damme N, De Vos M, et al. Macrophages expressing the scavenger receptor CD163: a link between immune alterations of the gut and synovial inflammation in spondyloarthropathy. J Pathol 2002;196:343-50. 